\title{
Article
}

Subscriber access provided by Gothenburg University Library

\section{Synergistic aqueous biphasic systems: a new paradigm for the 'one-pot' hydrometallurgical recovery of critical metals}

Nicolas Schaeffer, Matthieu Gras, Helena Passos, Vijetha Mogilireddy, Carlos M.N. Mendonça, Eduarda Pereira, Eric Chainet, Isabelle Billard, Joao A.P. Coutinho, and Nicolas (N.) Papaiconomou

ACS Sustainable Chem. Eng., Just Accepted Manuscript - DOI: 10.1021/

acssuschemeng.8b05754 - Publication Date (Web): 11 Dec 2018

Downloaded from http://pubs.acs.org on December 14, 2018

\section{Just Accepted}

"Just Accepted" manuscripts have been peer-reviewed and accepted for publication. They are posted online prior to technical editing, formatting for publication and author proofing. The American Chemical Society provides "Just Accepted" as a service to the research community to expedite the dissemination of scientific material as soon as possible after acceptance. "Just Accepted" manuscripts appear in full in PDF format accompanied by an HTML abstract. "Just Accepted" manuscripts have been fully peer reviewed, but should not be considered the official version of record. They are citable by the Digital Object Identifier (DOI®). "Just Accepted" is an optional service offered to authors. Therefore, the "Just Accepted" Web site may not include all articles that will be published in the journal. After a manuscript is technically edited and formatted, it will be removed from the "Just Accepted" Web site and published as an ASAP article. Note that technical editing may introduce minor changes to the manuscript text and/or graphics which could affect content, and all legal disclaimers and ethical guidelines that apply to the journal pertain. ACS cannot be held responsible for errors or consequences arising from the use of information contained in these "Just Accepted" manuscripts. 


\title{
Synergistic aqueous biphasic systems: a new paradigm for the 'one-pot' hydrometallurgical
} recovery of critical metals

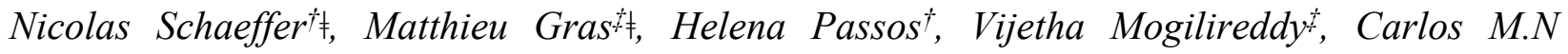 \\ Mendonçat, Eduarda Pereirat, Eric Chainet ${ }^{\dagger}$, Isabelle Billard ${ }^{\dagger}$, João A.P. Coutinho ${ }^{\dagger} *$, Nicolas \\ Papaiconomou* \\ ${ }^{\dagger}$ CICECO, Aveiro Institute of Materials, Department of Chemistry, University of Aveiro, 3810- \\ 193 Aveiro, Portugal. \\ $\$$ LEPMI - Universite Grenoble-Alpes, 1130 Rue de la Piscine, F-38000 Grenoble, France \\ * Corresponding author: nicolas.papaiconomou@lepmi.grenoble-inp.fr; jcoutinho@ua.pt \\ ₹ Nicolas Schaeffer and Matthieu Gras are equally contributing authors
}




\begin{abstract}
Acidic aqueous biphasic system (AcABS), in which the inorganic salt component of traditional aqueous biphasic system (ABS) is replaced by the inorganic acid inherently present in typical hydrometallurgical leachate solution, is shown to selectively separate cobalt from nickel, a separation relevant to the recycling of NiMH batteries. To overcome the limitation of electrodeposition in the presence of high acid concentration, a mixed ABS-AcABS approach is developed in which $\mathrm{HCl}$ is partially substituted by addition of a predictable amount of $\mathrm{NaCl}$. This synergistic ABS-AcABS system retains the metal extraction efficiency of AcABS whilst diminishing the acid concentration required to induce phase separation as well as its distribution to the ionic liquid-rich phase. Selective deposition of cobalt in the presence of co-extracted manganese impurities was achieved in AcABS, ABS and ABS-AcABS systems. The morphology and composition of the obtained deposits as well as the Faradic efficiency of the process can be altered by varying the $\mathrm{NaCl}$ to $\mathrm{HCl}$ ratio and water content, resulting in highly tailored cobalt deposits. These results highlight the potential of AcABS derived systems as a new extractionseparation platform for the integrated hydrometallurgical treatment of critical metals, from leaching to electrodeposition.
\end{abstract}

KEYWORDS: acidic aqueous biphasic systems, critical metals, ionic liquids, waste electrical and electronic equipment, electrodeposition 


\section{INTRODUCTION}

2 The extraction, separation and purification of critical metals from complex matrices such as

3 minerals or electronic wastes is technologically challenging, often requiring a series of demanding

4 processing steps. A traditional flowsheet for the hydrometallurgical treatment of metal feedstocks

5 follows a series of concentration (leaching), purification (solvent extraction) and refining stages

6 (electrodeposition or precipitation). ${ }^{1-5}$ Process intensification, i.e. the ability to conduct multiple

7 hydrometallurgical operations within a single processing unit, is of great interest industrially as

8 this can reduce the economic and environmental impact associated with metal consumption. In

9 this context, a sustainable, effective and affordable metal extraction process is an issue of critical

10 importance. To alleviate metal criticality and reduce the environmental impact of mining

11 operations, the development of a simple, robust and flexible platform is of particular relevance for

12 the recycling of metals from secondary 'ores'.

13 We recently proposed a 'one-pot' solution for the simultaneous leaching and selective extraction

14 of various critical metals using an ionic liquid-based acidic aqueous biphasic system (AcABS). ${ }^{6}$

15 Ionic liquids (ILs) are salts composed of asymmetric ions with disperse charge that are liquid at

16 room temperature. ${ }^{7}$ In the newly reported AcABS composed of the IL tributyltetradecyl

17 phosphonium chloride $\left(\left[\mathrm{P}_{44414}\right] \mathrm{Cl}\right)$, the very acid present in the leaching solution was used to salt-

18 out the IL. This is markedly different from conventional aqueous biphasic systems (ABS), such as

19 the previously reported $\left[\mathrm{P}_{44414}\right] \mathrm{Cl}-\mathrm{NaCl}$ - based $\mathrm{ABS}$ for metal extraction, ${ }^{8}$ in which the molar

20 entropy of hydration of an inorganic salt dictates the formation of a reversible biphasic system

21 composed of a salt-rich phase and organic-rich phase. ${ }^{9}$ Performing the extraction in aqueous media

22 reduces the overall environmental impact associated with IL application as (i) lower quantities are

23 required compared to solvent extraction, (ii) hydrophilic ILs are less toxic and more biodegradable 
24 than their hydrophobic counterparts and (iii) mass transfer properties are significantly improved

25 due to the lower solution viscosity, resulting in faster extraction kinetics. ${ }^{10-14}$

26 In this work, the scope AcABS processes is extended to investigate the extraction and separation

27 of $\mathrm{Co}(\mathrm{II})$, a critical metal, ${ }^{15}$ from $\mathrm{Ni}(\mathrm{II})$ and $\mathrm{Mn}(\mathrm{II})$ - a separation relevant to the recycling of nickel

28 metal hydride and lithium-ion batteries. ${ }^{16}$ To this end, a mixed ABS-AcABS approach is proposed

29 in which the $\mathrm{HCl}$ content required to induce phase separation in AcABS is predictably substituted

30 by small amounts of $\mathrm{NaCl}$, further accentuating the versatility of the proposed approach.

31 Synergistic ABS-AcABS systems retains the advantages of AcABS whilst diminishing the acid

32 concentration required to induce phase separation as well as its distribution to the IL-rich phase.

33 This enables the use of more environmentally friendly operating conditions and facilitates the

34 subsequent metal deposition from the IL-rich phase. Selective deposition of Co(II) is optimized as

35 a function of various parameters including water content, $\mathrm{HCl}$ concentration and $\mathrm{NaCl}$

36 concentration. The ability to directly deposit metals from the IL-rich phase opens the possibility

37 for a fully integrated approach to the leaching, separation and deposition of critical metals from 38 complex sources.

\section{METHODOLOGY}

\section{Materials and Instrumentation}

42 A detailed description of the compounds used as well as the instrumentation employed is 43 provided in the 'Methodology' section of the Supplementary information. The chemicals were 44 used as received without further purification. 


\section{Determination of mixed ABS-AcABS systems for metal extraction}

46 It is important to emphasise that three different separation systems are employed in this work:

47 two ternary systems composed of $\left[\mathrm{P}_{44414}\right] \mathrm{Cl}-\mathrm{HCl}-\mathrm{H}_{2} \mathrm{O}(\mathrm{AcABS})$ and $\left[\mathrm{P}_{44414}\right] \mathrm{Cl}-\mathrm{NaCl}-\mathrm{H}_{2} \mathrm{O}(\mathrm{ABS})$

48 respectively and a quaternary system $\left[\mathrm{P}_{44414}\right] \mathrm{Cl}-\mathrm{HCl}-\mathrm{NaCl}-\mathrm{H}_{2} \mathrm{O}$ referred to as $\mathrm{ABS}-\mathrm{AcABS}$. The

49 phase diagrams for the quaternary system ABS-AcABS containing a fixed $\mathrm{NaCl}$ concentration (1

50 wt.\%, 2 wt.\% and 4 wt.\%) were determined through the cloud point titration method in a

51 temperature-controlled cell at $298 \mathrm{~K}$ under agitation and atmospheric pressure. The concentration

52 of $\mathrm{NaCl}$ was identical ( 1 wt.\%, 2 wt.\% and 4 wt.\%) in all solutions used as to keep its concentration

53 constant throughout the cloud point titration procedure. The quaternary system compositions were

54 determined by the weight quantification of all components added within an uncertainty of $\pm 10^{-3} \mathrm{~g}$.

55 The detailed experimental procedure adopted is described in a previous work. ${ }^{17}$ The extraction and 56 separation of $\mathrm{Co}(\mathrm{II})$ from $\mathrm{Ni}(\mathrm{II})$ and $\mathrm{Mn}(\mathrm{II})$ in different ABS-AcABS mixtures of total mass $5 \mathrm{~g}$ 57 containing 30 wt.\% $\left[\mathrm{P}_{44414}\right] \mathrm{Cl}$ was studied as a function of the $\mathrm{HCl}$ to $\mathrm{NaCl}$ ratio. A mixed metal 58 ion solution containing 0.1 mol.L $\mathrm{L}^{-1} \mathrm{CoCl}_{2} \cdot 6 \mathrm{H}_{2} \mathrm{O}, 0.1$ mol.L $\mathrm{L}^{-1} \mathrm{NiCl}_{2} \cdot 6 \mathrm{H}_{2} \mathrm{O}$ and 0.1 mol.L $\mathrm{L}^{-1}$ $59 \mathrm{MnCl}_{2} \cdot 4 \mathrm{H}_{2} \mathrm{O}$ was used for all experiments. Solutions were mechanically agitated for 5 min at 298

$60 \mathrm{~K}$ until the complete dissolution of the IL. The resulting mixture was left to phase separate $60 \mathrm{~min}$ 61 in a thermostatic bath at $298 \mathrm{~K}$. The volume of each phase of the ABS-AcABS was measured and 62 aliquots of the upper and lower phases were collected for metal concentration analysis by 63 inductively coupled plasma optical emission spectroscopy (ICP-OES) after appropriate dilution.

64 The chloride, acid and water content of the IL-rich phase (top phase) was also determined after 65 separation of the phases. The extraction efficiency $(\% \mathrm{EE})$ was calculated as follows: ${ }^{6}$

$66 \% \mathrm{EE}=\frac{\frac{[M]_{0} V_{\text {initial }}}{V_{\text {low }}}-[M]_{\text {low }}}{[M]_{0}} \times 100$ 
67 where $[\mathrm{M}]_{0}$ is the initial metal concentration of the metal in solution before extraction (i.e. before

68 addition of the IL). $V_{\text {initial }}$ is the volume in $\mathrm{mL}$ of the mixture before extraction whilst $V_{\text {low }}$ is the

69 volumes, expressed in $\mathrm{mL}$, of the lower phase after extraction. $[\mathrm{M}]_{\text {low }}$ is the concentration of the

70 metal ion in the lower phase after extraction.

\section{Electrodeposition of Co(II) from ABS-AcABS}

72 Electrochemical investigations including chronoamperometry and cyclic voltammetry (CV) 73 were carried out using a Metrohm Autolab potentiostat controlled with the GPES software. A 74 three-electrode system was used consisting of a glassy carbon (GC) working electrode (3 $\mathrm{mm}$ 75 diameter), an iridium counter electrode and a silver chloride $(\mathrm{Ag} / \mathrm{AgCl})$ reference electrode. The 76 working electrode was polished with diamond paste, rinsed and dried prior to all measurements. 77 All cyclic voltammograms of single $0.1 \mathrm{~mol} \cdot \mathrm{L}^{-1} \mathrm{Co}(\mathrm{II})$ aqueous solutions were obtained at $298 \mathrm{~K}$ 78 and at a scanning rate of $0.01{\mathrm{~V} . \mathrm{s}^{-1}}$ with varying $\left[\mathrm{P}_{44414}\right] \mathrm{Cl}$ (from 0 to 20 wt.\%) and $\mathrm{HCl}$ 79 concentrations ( 0 to 8 mol. $\left.\mathrm{L}^{-1}\right)$.

80 Chronometric deposition experiments were performed in the following three systems: ABS, 81 AcABS and ABS-AcABS (with and without the addition of water). Compositions of all systems 82 are presented in Table $\mathrm{S} 1$ in the ESI. After extraction from a single metal solution containing 0.1 83 mol. $\mathrm{L}^{-1}$ of $\mathrm{CoCl}_{2} \cdot 6 \mathrm{H}_{2} \mathrm{O}$ or a mixed solution of 0.1 mol. $\mathrm{L}^{-1}$ of $\mathrm{CoCl}_{2} \cdot 6 \mathrm{H}_{2} \mathrm{O}, \mathrm{NiCl}_{2} \cdot 6 \mathrm{H}_{2} \mathrm{O}$ and $84 \mathrm{MnCl}_{2} \cdot 4 \mathrm{H}_{2} \mathrm{O}$, the IL-rich phase was isolated from the aqueous one. $\mathrm{CV}$ experiments were carried 85 out under agitation in a potential range of -2.50 to $2.00 \mathrm{~V} v s$. $\mathrm{Ag} / \mathrm{AgCl}$ at a scan rate of $0.01 \mathrm{~V} . \mathrm{s}^{-1}$. 86 Electrodeposition of metals was undertaken by chronoamperometry agitation at a fixed potential 87 of $-2.00 \mathrm{~V} v s . \mathrm{Ag} / \mathrm{AgCl}$ during one hour. The three systems namely, AcABS, ABS and ABS88 AcABS depicted in Table S1 were studied. A fourth system was considered to investigate the 
89 impact of the water content on the deposition. After separating and isolating the phases from the 90 system ABS-AcABS, the IL-rich phase was diluted in a minimum of water ( $0.2 \mathrm{~g}$ of water per

91 gram of isolated IL-rich phase) until the solution colour transitioned from deep blue to light red.

92 This well-known colour change is due to the transition of blue chloride-complexes $\left(\mathrm{CoCl}_{4}^{2-}\right.$ or $\left.93 \mathrm{CoCl}_{3}{ }^{2-}\right)$ to the formation of a red cobalt hexahydrate complex, $\mathrm{Co}^{2+}\left(\mathrm{H}_{2} \mathrm{O}\right)_{6} \cdot{ }^{18}$ This system is 94 referred to as "ABS-AcABs-diluted" in this work.

95 Obtained deposits were analysed by SEM-Energy Dispersive Spectroscopy (SEM-EDS) for 96 single metal extractions. Metallic deposits obtained after selective deposition of cobalt in 97 multielemental solutions were analysed through X-ray Diffraction (XRD). In the latter case, the 98 metal was fully leached in $5 \mathrm{~mL}$ of 4 mol. $\mathrm{L}^{-1}$ nitric acid $\left(\mathrm{HNO}_{3}\right)$ in order to investigate (i) the 99 purity of the metal and (ii) the Faradic efficiency of the electrodeposition $\left(\mathrm{E}_{\mathrm{F}}\right)$. The Faradic yield 100 corresponds to the ratio between the experimental and theoretical conversion of $\operatorname{Co}(\mathrm{II})$ to $\operatorname{Co}(0)$ 101 during electrodeposition. $E_{\mathrm{F}}$ was calculated according to the following equation:

$102 E_{F}=\frac{C_{C_{0}} \times V_{\mathrm{HNO}_{3}}}{\frac{\int_{0}^{t}(t) d t}{n F}} \times 100$

103 where $\mathrm{C}_{\mathrm{Co}}$ represents the concentration of cobalt in mol. $\mathrm{L}^{-1}$ in the aqueous phase containing nitric 104 acid, used to leach the deposits. $\mathrm{V}_{\mathrm{HNO}}$ is the volume of the nitric acid solution in L. I (A) represents 105 the current produced during chronoamperometry measurements for a given time $t$ in seconds. $F$ 106 and $n$ stand for the Faraday constant and the number of moles of electrons exchanged during the 107 reduction respectively. 


\section{RESULTS AND DISCUSSION}

\section{Development of mixed ABS-AcABS systems for metal extraction}

112 The innovation of AcABS lies in its ability to extract metals directly from leachates just by 113 adding a carefully selected IL. However, optimal extraction and separation of $\operatorname{Co}(\mathrm{II})$ in the $114\left[\mathrm{P}_{44414}\right] \mathrm{Cl}-\mathrm{HCl}-\mathrm{H}_{2} \mathrm{O}$ AcABS was shown to occur for highly concentrated solutions of $\mathrm{HCl}$ above 1158 mol.L $\mathrm{L}^{-1}$ or $\sim 25$ wt. $\%$, considerably more concentrated than most common leaching solutions (cf. 116 Figure $\mathrm{S} 1$ of the ESI). A full description $\mathrm{Co}(\mathrm{II}), \mathrm{Ni}(\mathrm{II})$ and $\mathrm{Mn}(\mathrm{II})$ extraction in AcABS is provided 117 in the "Metal extraction in the $\left[\mathrm{P}_{44414}\right] \mathrm{Cl}-\mathrm{HCl}-\mathrm{H}_{2} \mathrm{O}$ AcABS" section in the ESI. This includes the 118 effect of $\mathrm{HCl}$ concentration in $\mathrm{AcABS}$ on the partition of $\left[\mathrm{H}_{3} \mathrm{O}\right]^{+}, \mathrm{Cl}^{-}$and $\mathrm{H}_{2} \mathrm{O}$ to the IL-rich phase 119 (Table S2, ESI), the IL-rich phase viscosity before and after metal extraction (Figure S2, ESI) and 120 the influence of $\mathrm{Co}$ (II) feed concentration on the extraction efficiency and system properties of 121 AcABS (Figure S3 and S4, ESI).

122 However, the addition of extra $\mathrm{HCl}$ to leachates to induce AcABS formation and the efficient 123 extraction of $\mathrm{Co}(\mathrm{II})$ is not realistic from an industrial perspective due to i) the corrosivity of $\mathrm{HCl}$ 124 and ii) the increased cost of solution neutralisation after extraction. Furthermore, even small $\mathrm{HCl}$ 125 concentrations can inhibit the subsequent electro-deposition of $\mathrm{Co}$ (II) due to the narrowing of the 126 electrochemical window caused by the reduction of $\left[\mathrm{H}_{3} \mathrm{O}\right]^{+}\left(c f\right.$. Figure $\mathrm{S} 5$ in ESI). $\left[\mathrm{P}_{44414}\right] \mathrm{Cl}$ was 127 shown to form ABS with a wide range of chloride salts. ${ }^{19}$ As such, we propose a mixed ABS128 AcABS system using mixtures of $\mathrm{HCl} / \mathrm{NaCl}$ capable of efficiently separating $\mathrm{Co}(\mathrm{II})$ from $\mathrm{Ni}$ (II) 129 and $\mathrm{Mn}(\mathrm{II})$ from any chloride-containing aqueous solution, even at low $\mathrm{HCl}$ concentrations. It is 130 important to stress that some degree of solution acidity is required leach metals and to prevent 131 metal hydrolysis common at the high $\mathrm{pH}$ of typical ABS. 
132 The binodal curves for $\left[\mathrm{P}_{44414}\right] \mathrm{Cl}-\mathrm{HCl}-\mathrm{H}_{2} \mathrm{O}$ systems containing $1 \mathrm{wt} . \%, 2 \mathrm{wt} \%$ and $4 \mathrm{wt} \%$ of $\mathrm{NaCl}$ 133 at $T=298 \mathrm{~K}$ are presented in Figure $1 \mathrm{~A}$. As expected from the lower cloud point of the $\left[\mathrm{P}_{44414}\right] \mathrm{Cl}$ $134 \mathrm{NaCl}-\mathrm{H}_{2} \mathrm{O}$ system compared to that of $\mathrm{HCl},{ }^{19}$ the addition of a small concentration of $\mathrm{NaCl}$ results 135 in a large decrease in the corresponding $\mathrm{HCl}$ concentration required to induce phase separation. 136 For $15 \mathrm{wt.} \%\left[\mathrm{P}_{44414}\right] \mathrm{Cl}$, approximately $21 \mathrm{wt} . \%$ of $\mathrm{HCl}$ is required compared to $6.5 \mathrm{wt} . \% \mathrm{HCl}$ for 137 a mixed ABS-AcABS containing 4 wt. $\% \mathrm{NaCl}$. An additional benefit of the presented ABS138 AcABS system is the predictable shift in the binodal position with increasing $\mathrm{NaCl}$ concentration 139 as shown in Figure 1B. For $\left[\mathrm{P}_{44414}\right] \mathrm{Cl}$ concentrations above $5 \mathrm{wt} . \%$, the binodals in Figure 1A are 140 roughly parallel. This allows the following simplification to be made: the addition of $1 \mathrm{wt} . \% \mathrm{NaCl}$ 141 decreases the $\mathrm{HCl}$ requirement by approximately $3.4 \mathrm{wt} . \%$. The proposed linear correlation is only 142 valid for ABS-AcABS containing up to of $4 \mathrm{wt} . \% \mathrm{NaCl}$. Addition of $\mathrm{NaCl}$ above $4 \mathrm{wt} . \%$ does not 143 provide the same relative $\mathrm{HCl}$ decrease as below this salt concentration (Figure S6 in ESI). This 144 appears as the limit for the synergistic effect of $\mathrm{NaCl}$ with $\mathrm{HCl}$ in ABS-AcABS. 

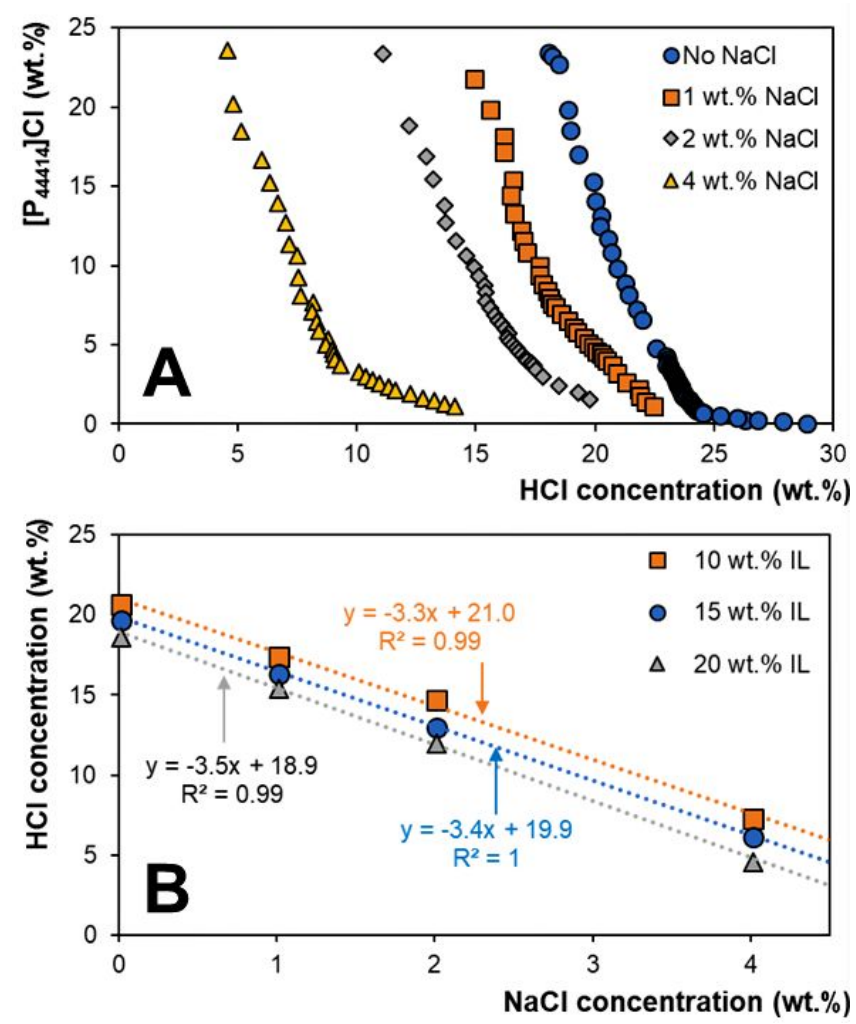

147 Figure 1. (A) The effect of $\mathrm{NaCl}$ concentration on the binodal curve of $\left[\mathrm{P}_{44414}\right] \mathrm{Cl}-\mathrm{HCl}-\mathrm{H}_{2} \mathrm{O}$ system 148 at $298 \mathrm{~K}$ (binodal data is provided in Table S3 in the ESI). (B) Reduction in the HCl concentration 149 required to induce phase separation at a fixed $\mathrm{NaCl}$ concentration for $10 \mathrm{wt} \% \%, 15$ wt.\% and 20 150 wt. $\%\left[\mathrm{P}_{44414}\right] \mathrm{Cl}$

152 The partition of $\mathrm{Co}(\mathrm{II}), \mathrm{Ni}(\mathrm{II})$ and $\mathrm{Mn}(\mathrm{II})$ from a multielement solution containing 0.1 mol.L $\mathrm{L}^{-1}$ 153 of each respective metal ion was attempted for eight ABS-AcABS systems at different $\mathrm{HCl}: \mathrm{NaCl}$ 154 ratio $(T=298 \mathrm{~K})$. The system compositions are given in Table S4 of the ESI and their respective 155 metal extraction efficiency and the concentration of $\mathrm{Cl}^{-},\left[\mathrm{H}_{3} \mathrm{O}\right]^{+}$and $\mathrm{H}_{2} \mathrm{O}$ in the IL-rich phase after 156 extraction and phase separation are presented in Figure 2-3 and Table S4. The concentration of the $157\left[\mathrm{P}_{44414}\right]^{+}$cation in the aqueous phase was found to be below the detection limit for all tested systems 
158 and is not included. The results in Figure 2 show that for all systems, there is little variation in the 159 extraction efficiency of the studied metal ions as one moves from and ABS to AcABS despite the 160 large variation in the total chloride concentration. Co(II) was extracted to the IL-rich phase whilst $161 \mathrm{Ni}(\mathrm{II})$ remained in the aqueous phase and $\mathrm{Mn}$ (II) partitioned between the two, with a slight increase 162 in $\mathrm{Mn}(\mathrm{II})$ extraction at higher $\mathrm{NaCl}$ concentrations. These results are in accordance with previously 163 reported $\mathrm{Co}(\mathrm{II})$ and $\mathrm{Ni}(\mathrm{II})$ extraction from $\left[\mathrm{P}_{44414}\right] \mathrm{Cl}-\mathrm{NaCl}_{-} \mathrm{H}_{2} \mathrm{O}$ ABS and $\left[\mathrm{P}_{44414}\right] \mathrm{Cl}-\mathrm{HCl}-\mathrm{H}_{2} \mathrm{O}$ $164 \mathrm{AcABS}^{6,8}$ as well as those using hydrophobic phosphonium based-ILs in traditional liquid-liquid 165 extraction. ${ }^{13-14,16,20}$

166 ILs incorporating quaternary phosphonium cations are known to extract anionic metal 167 complexes such as those formed by $\mathrm{Co}(\mathrm{II}), \mathrm{Cu}(\mathrm{II}), \mathrm{Fe}(\mathrm{III}), \mathrm{Pd}(\mathrm{II})$, or $\mathrm{Pt}(\mathrm{IV})$ at high halide 168 concentrations through the formation of a hydrophobic pair between the anionic metal complex 169 and the cation of the IL. ${ }^{6,8,13-14,20-21} \mathrm{Ni}(\mathrm{II})$ exhibits a limited coordination with chloride anions, 170 highlighted by the low complexation constant of $\mathrm{NiCl}^{+}\left(\mathrm{k}_{1}{ }^{\mathrm{Ni2}+}=0.07\right) .{ }^{18}$ The inability of $\mathrm{Ni}$ (II) to 171 form anionic chloro-complexes in water results in low extraction yields due to its inability to form 172 an ion pair with the IL cation. The intermediate complexation constant of $\mathrm{Mn}$ (II) with $\mathrm{Cl}^{-}\left(\mathrm{k}_{1}{ }^{\mathrm{Mn} 2+}\right.$ $173=0.33)$ compared to $\mathrm{Ni}(\mathrm{II})$ and $\mathrm{Co}(\mathrm{II})\left(\mathrm{k}_{1}{ }^{\mathrm{C} 2+}=0.40\right)^{18}$ is reflected in its extraction efficiency

174 (Figure 2). The speciation of $\mathrm{Co}(\mathrm{II})$ is highly dependent on the ratio of $\mathrm{Co}$ (II) concentration to 175 chloride concentration in solution, the anionic species $\mathrm{CoCl}_{3}{ }^{-}$and $\mathrm{CoCl}_{4}{ }^{2-}$ can be found at high $176 \mathrm{HCl}$ concentrations. ${ }^{18}$ This transition from $\mathrm{Co}\left(\mathrm{H}_{2} \mathrm{O}\right)_{6}{ }^{2+}$ found in aqueous solutions to negatively 177 charged $\mathrm{Co}(\mathrm{II})$ complexes can be visually observed as the solution changes color from pinkish red 178 to deep blue, the same as the color of the IL-rich phase after extraction. A previous study on the 179 extraction of $\mathrm{Co}(\mathrm{II})$ using $\left[\mathrm{P}_{44414}\right] \mathrm{Cl}$ confirmed that $\mathrm{Co}(\mathrm{II})$ is predominantly extracted as the 
$180 \mathrm{CoCl}_{4}{ }^{2-}$ species within the IL phase. ${ }^{6,8}$ The speciation of $\mathrm{Co}(\mathrm{II})$ is highly relevant for its subsequent 181 electrodeposition from IL solutions and will be addressed further on. ${ }^{22}$

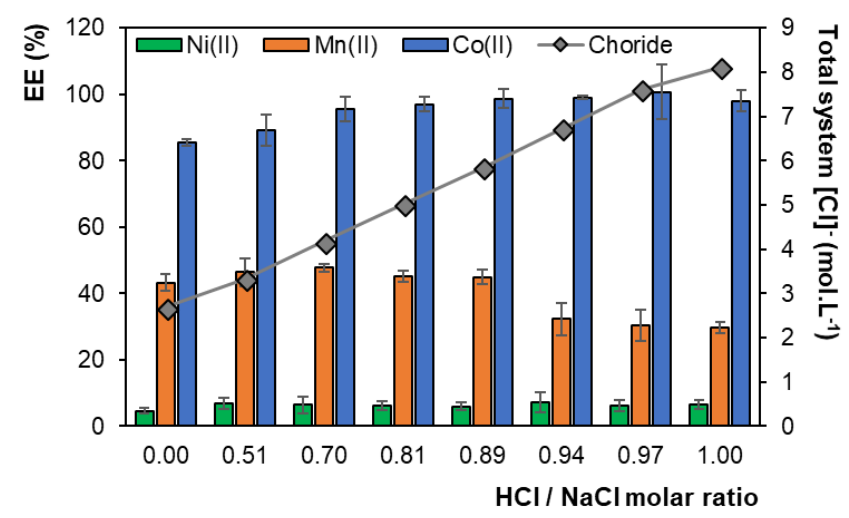

184 Figure 2. $\mathrm{Co}(\mathrm{II}), \mathrm{Mn}(\mathrm{II})$ and $\mathrm{Ni}(\mathrm{II})$ extraction efficiencies in ABS-AcABS system with varying $185 \mathrm{NaCl}$ to $\mathrm{HCl}$ concentrations at $298 \mathrm{~K}$. System compositions are provided in Table S4 of the ESI.

On a molar basis, significantly less $\mathrm{Cl}^{-}$is required to induce ABS phase separation and $\mathrm{Co}(\mathrm{II})$ 188 extraction when $\mathrm{NaCl}$ is employed compared to $\mathrm{HCl} . \mathrm{NaCl}$ was shown to be a more efficient 189 salting-out agent than $\mathrm{HCl}$ for the liquid-liquid demixing of $\left[\mathrm{P}_{44414}\right]$ Cl-based $\mathrm{ABS} .{ }^{19}$ Extraction of $190 \mathrm{Co}(\mathrm{II})$ is close to quantitative for $\mathrm{HCl}: \mathrm{NaCl}$ ratio of 0.7 or greater. It is postulated that in such 191 systems, the $\mathrm{Cl}^{-}$provides the necessary chloride to form anionic chlorocobalt complexes whilst the 192 greater salting-out effect of $\mathrm{Na}^{+}$compared to that of $\left[\mathrm{H}_{3} \mathrm{O}\right]^{+}$promotes the transition of the less 193 hydrophilic $\mathrm{CoCl}_{3}{ }^{-}$and $\mathrm{CoCl}_{4}{ }^{2-}$ species to the IL-rich phase. This supports the claim that a mixed 194 ABS-AcABS system for metal extraction combines the advantages and flexibility of AcABS with 195 those of ABS with no loss in metal extraction efficiency. 
196 The partition behaviour of the acid and water to the IL-rich phase in mixed ABS-AcABS 197 presents an interesting behaviour based on the ratio of $\mathrm{HCl}$ to $\mathrm{NaCl}$ as shown in Figure 3. The 198 water content of the IL-rich phase is low for all the studied systems, decreasing down to a minimum 199 of 7 wt. $\% \mathrm{H}_{2} \mathrm{O}$ for an ABS-AcABS composition of 30 wt.\% [ $\left.\mathrm{P}_{44414}\right] \mathrm{Cl}, 10.8$ wt.\% $\mathrm{HCl}$ and 4.0 200 wt.\% $\mathrm{NaCl}$. The water content increases as $\mathrm{NaCl}$ is substituted by $\mathrm{HCl}$ from 10.6 wt. $\%$ in $\mathrm{ABS}$ 201 and reaching $21.1 \mathrm{wt} . \%$ for the pure AcABS in line with the greater salting-out potential of $\mathrm{NaCl}$ 202 compared to $\mathrm{HCl} .{ }^{19}$ Furthermore, the acid concentration in the IL-rich phase does not significantly 203 increase whilst $\mathrm{NaCl}$ is the primary driver $(\mathrm{HCl}: \mathrm{NaCl}$ molar ratio $<0.89)$ for the phase separation 204 of ABS-AcABS. From the presented results, two conclusions can be inferred of great relevance 205 for the subsequent electrodeposition of $\mathrm{Co}(\mathrm{II})$ from a $\left[\mathrm{P}_{44414}\right] \mathrm{Cl}$-rich phase. Firstly, a mixed ABS206 AcABS system can be predictably tuned with little appreciable variation in metal extraction 207 compared to simple ABS or AcABS systems. Secondly, a compromise is required in the $\mathrm{HCl}$ to $208 \mathrm{NaCl}$ ratio of $\mathrm{ABS}-\mathrm{AcABS}$. Higher $\mathrm{NaCl}$ concentrations reduce the acid and chloride migration to 209 the IL-rich phase at the expense of a lower water content compared to simple AcABS. The high 210 viscosity of loaded $\left[\mathrm{P}_{44414}\right] \mathrm{Cl}$ solutions can reduce the diffusion of $\mathrm{Co}(\mathrm{II})$ as well as cause losses 211 during manipulation. However, minimizing the acid concentration will facilitate the deposition of $212 \mathrm{Co}(\mathrm{II})$ from $\left[\mathrm{P}_{44414}\right] \mathrm{Cl}$ solutions. An additional consideration is that the water content, and 213 therefore the viscosity, of the loaded $\left[\mathrm{P}_{44414}\right] \mathrm{Cl}$-rich phase once isolate can be controlled by dilution 214 with water. 


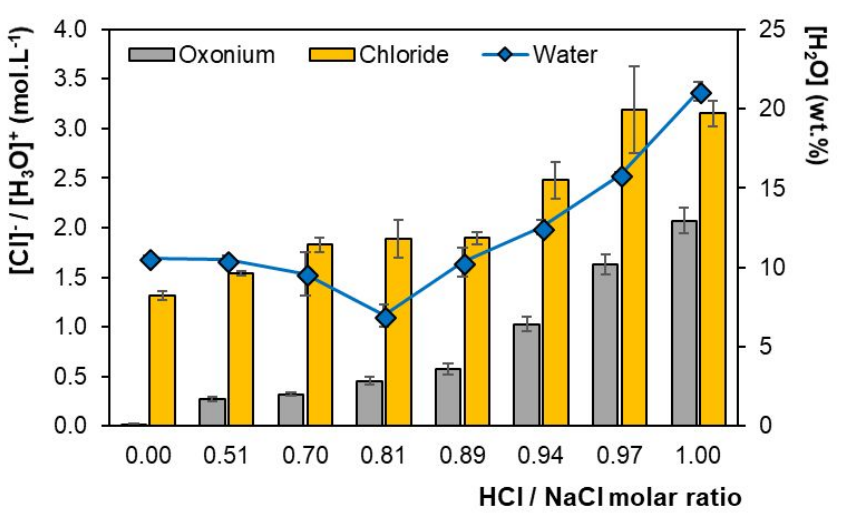

217 Figure 3. Concentration of acid $\left(\left[\mathrm{H}_{3} \mathrm{O}\right]^{+}\right)$, chloride anion and water in the $\left[\mathrm{P}_{44414}\right] \mathrm{Cl}$-rich phase 218 after metal extraction in ABS-AcABS system with varying $\mathrm{NaCl}$ to $\mathrm{HCl}$ concentrations at $298 \mathrm{~K}$. 219 System compositions, including the partition behavior of the acid and water to the IL-rich phase, 220 are provided in Table S4 of the ESI.

\section{Electrochemical behaviour of Co(II) in ABS-AcABS systems}

223 Having demonstrated the separation of $\mathrm{Co}(\mathrm{II})$ from $\mathrm{Ni}(\mathrm{II})$ and $\mathrm{Mn}(\mathrm{II})$ in AcABS and ABS224 AcABS as well as the partitioning of the system components relevant to the subsequent deposition 225 of $\mathrm{Co}(\mathrm{II})$, the electrochemical behaviour of studied system is now investigated. The influence of 226 the hydrophilic $\left[\mathrm{P}_{44414}\right] \mathrm{Cl}$ in aqueous solutions on the reduction potential of $\mathrm{Co}(\mathrm{II})$ is presented in 227 Figure 4. The presence of the IL in aqueous solution lowers the kinetics of water to hydrogen 228 reduction ( $c f$. Figure 4A), in line with the wide electrochemical window of phosphonium-based 229 ILs. ${ }^{23-24} \mathrm{Co}(\mathrm{II})$ is known to reduce to metallic cobalt at a potential of $-0.28 \mathrm{~V} v s$. ENH, this is to 230 say, $-0.50 \mathrm{~V}$ vs. $\mathrm{Ag} / \mathrm{AgCl}{ }^{25} \mathrm{In}$ accordance with the literature, the $\mathrm{CV}$ of an aqueous $0.1 \mathrm{~mol}^{-\mathrm{L}^{-1}}$ $231 \mathrm{Co}(\mathrm{II})$ solution (Figure 4A, dashed line) presents an inset reducing peak at $-0.42 \mathrm{~V}$ and a minimum 232 at $-1.0 \mathrm{~V} v s . \mathrm{Ag} / \mathrm{AgCl}$. A large oxidation peak is also observed from 0.42 to $0.59 \mathrm{~V} v s$. $\mathrm{Ag} / \mathrm{AgCl}$, 
233 confirming that cobalt can be oxidized reversibly. The addition of increasing amounts of $\left[\mathrm{P}_{44414}\right] \mathrm{Cl}$

234 from 0 to $10 \mathrm{wt}$ \% IL results in a decrease in the cathodic peak potential for cobalt $\left(\mathrm{E}^{\mathrm{Red}} \mathrm{Co}\right)$ from $235-0.42$ to $-1.06 \mathrm{~V}$ vs $\mathrm{Ag} / \mathrm{AgCl}$. When the concentration of IL exceeds $10 \mathrm{wt} \%$, the reduction peak 236 potential remains constant ( $c f$. Figure 4B). This shift in the reduction peak is a strong indication of 237 a change in the complexation of $\mathrm{Co}$ (II) in the presence of the chloride anions from the IL. The 238 anionic cobalt complexes $\mathrm{CoCl}_{3}{ }^{-}$and $\mathrm{CoCl}_{4}{ }^{2-}$ are the predominant complexes reported in chloride 239 based ILs. ${ }^{13-14,22,26}$ Furthermore, whilst the $\mathrm{CoCl}_{3}{ }^{-}$was shown to be electrochemically active in 240 ILs, the complex $\mathrm{CoCl}_{4}{ }^{2-}$ was not. ${ }^{22}$ This suggests that a high chloride concentration is inhibiting 241 the deposition of $\operatorname{Co}(0)$. This is in accordance with the Nernst law, which states that changes in 242 the speciation has an influence on the standard reduction potential of metallic species.

243 However, complexation of chlorides is insufficient to explain the magnitude of the shift in the 244 reduction potential. The electrochemical kinetic behaviour of nickel electrodeposition was 245 previously studied in acidic aqueous phases and lead to the intermediate formation of $\mathrm{Ni}(\mathrm{OH})$ 246 adsorbed species. ${ }^{27-29}$ Similarly, cobalt is assumed to present the following reduction mechanism 247 in water:

$248 \mathrm{Co}^{2+}+\mathrm{e}^{-}+\mathrm{OH}^{-} \leftrightarrow \mathrm{Co}(\mathrm{OH})_{\mathrm{ads}}$

$249 \mathrm{Co}(\mathrm{OH})_{\mathrm{ads}}+\mathrm{e}^{-} \leftrightarrow \mathrm{Co}+\mathrm{OH}^{-}$

250 Elevated concentrations of ILs could inhibit the formation of the intermediate complex cobalt(I) 251 hydroxide adsorbed species and therefore reduce the kinetic of reduction of $\mathrm{Co}$ (II).

252 The intensity of all reduction peaks decreases with the increasing IL concentration due to the 253 higher viscosity and therefore lower kinetics of the IL-concentrated systems compared to the pure 254 water system. Finally, an unveiled trend can be observed for mixtures containing $5 \mathrm{wt} . \%\left[\mathrm{P}_{44414}\right] \mathrm{Cl}$ 
255 or more with the emergence of a small reduction peak close to $-0.5 \mathrm{~V} v s$. $\mathrm{Ag} / \mathrm{AgCl}$ (Figure $5 \mathrm{~A}$, 256 inset). This is attributed to the reduction of $\mathrm{Co}(\mathrm{II})$ to $\mathrm{Co}(\mathrm{I})$. ILs provide a better environment for 257 the stabilisation of intermediate metal oxidation states compared to water. For example, the 258 presence of water was shown to significantly affect the voltammetric behaviour of Co(II) in the 259 ethylammonium nitrate IL and the oxidation of $\mathrm{Co}(\mathrm{II})$ to $\mathrm{Co}(\mathrm{III}) .{ }^{30}$
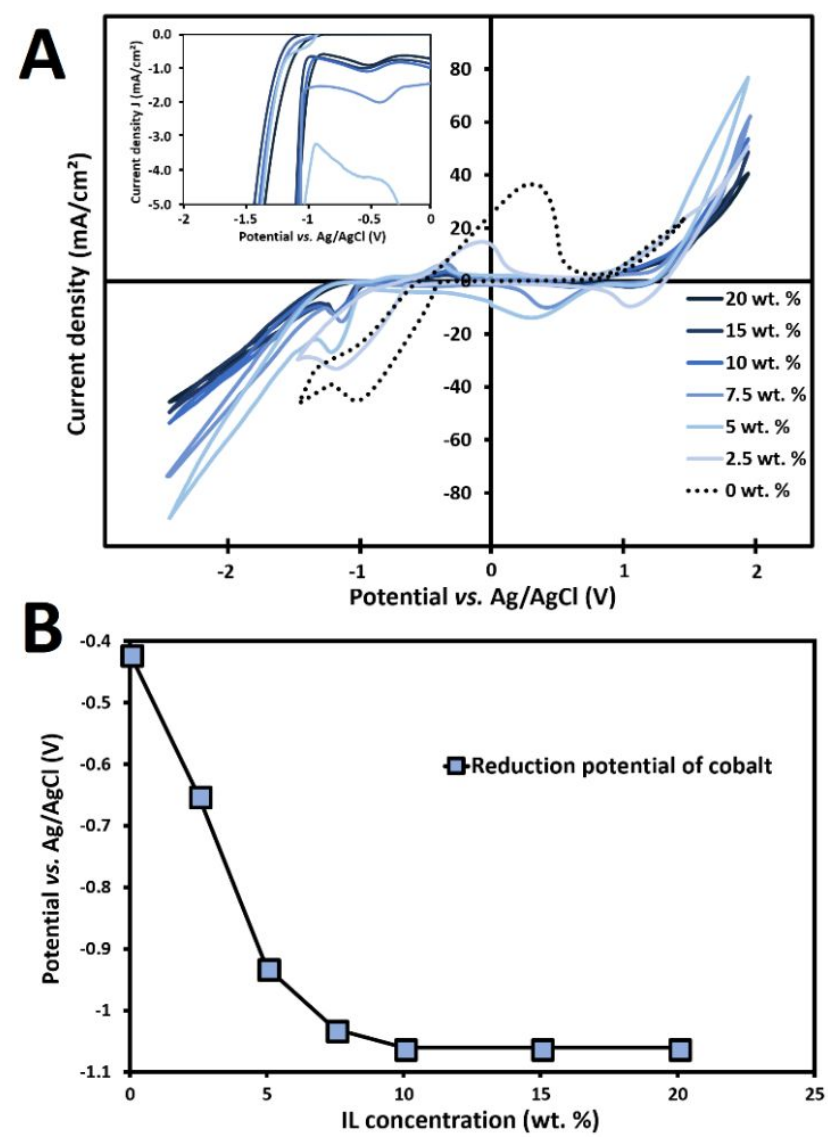

262 Figure 4. (A) CV experiments at a $0.01 \mathrm{~V} \cdot \mathrm{s}^{-1}$ scan rate of various solutions containing $0.1 \mathrm{~mol} . \mathrm{L}^{-}$ $263{ }^{1}$ of $\mathrm{Co}(\mathrm{II})$ and concentration of $\left[\mathrm{P}_{44414}\right] \mathrm{Cl}$ ranging between 0 (black dotted line) and $20 \mathrm{wt} . \%$ 264 (light to dark blue colours). (B) Evolution of the inset peak corresponding to the reduction of Co(II) 265 to $\mathrm{Co}(0)$ as a function of the concentration of $\left[\mathrm{P}_{44414}\right] \mathrm{Cl}$. 
$267 \mathrm{CV}$ analysis at a scan rate of $0.01 \mathrm{~V} . \mathrm{s}^{-1}$ and $298 \mathrm{~K}$ on a GC working electrode was carried out in 268 the four systems AcABS, ABS and ABS-AcABS (both undiluted and diluted) after extraction from 2690.1 mol.L-1 $\mathrm{Co}(\mathrm{II})$ solutions. The solution compositions of the studied systems are listed in Table 270 S1. The CV scans are presented in Figure 5. Electrodeposition of Co(II) was performed during one 271 hour on a GC electrode under agitation. The electrodes were qualitatively and semi-quantitatively 272 analyzed via SEM-SE and SEM-ESD respectively. The morphology and composition of the 273 obtained deposits are presented in Figure 6 and Table 1 respectively.

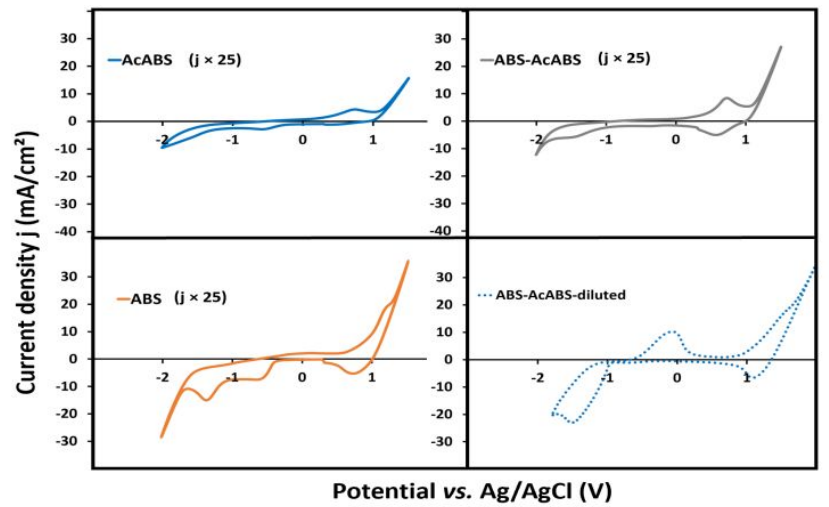

276 Figure 5. CV of various systems after extraction of cobalt in an aqueous solution containing 0.1 277 mol.L $\mathrm{L}^{-1} \mathrm{Co}(\mathrm{II})$. Scanning rate: $0.01 \mathrm{~V} \cdot \mathrm{s}^{-1}$. Current densities (J) are multiplied by 25 for the ABS, 278 AcABS and ABS-AcABS systems.

280 Starting with the ABS system, first reported by Onghena et al. ${ }^{8}$ composed of $\left[\mathrm{P}_{44414}\right] \mathrm{Cl}-\mathrm{NaCl}-$ $281 \mathrm{H}_{2} \mathrm{O}$, a reduction peak ( $\mathrm{Co}(\mathrm{II})$ to $\left.\mathrm{Co}(0)\right)$ with an onset point at $-1.07 \mathrm{~V} v$ s. $\mathrm{Ag} / \mathrm{AgCl}$ can be observed 282 (Figure 5, orange line). This is in full agreement with our previous result showing that $\mathrm{E}^{\mathrm{Red}} \mathrm{Co}_{\mathrm{o}}=-$ $2831.06 \mathrm{~V} v s . \mathrm{Ag} / \mathrm{AgCl}$ for systems containing $10 \mathrm{wt} . \%$ or more $\left[\mathrm{P}_{44414}\right] \mathrm{Cl}$. After inducing a potential 
284 of $-2.00 \mathrm{~V} v s . \mathrm{Ag} / \mathrm{AgCl}$ to the solution, EDS analysis of the obtained deposit on the GC electrode 285 surface indicates a high purity cobalt deposit of 98.9 mol.\% (Table 1). No significant quantities of 286 chloride or phosphonium are recorded. The morphology of the obtained deposit is that of 287 micrometre-scale dendrites, characteristic of metallic cobalt in aqueous solutions. ${ }^{31}$ Despite the 288 lack of visible $\mathrm{Co}(0)$ reduction peak in the $\left[\mathrm{P}_{44414}\right] \mathrm{Cl}-\mathrm{HCl}-\mathrm{H}_{2} \mathrm{O}$ AcABS (Figure 5, purple line), 289 small particles were identified on the GC electrode after electrodeposition. This is a direct 290 consequence of the large concentration of acid after extraction in the top phase $\left(\left[\mathrm{H}_{3} \mathrm{O}\right]^{+}=3.0 \pm 0.26\right.$ 291 mol. $\left.\mathrm{L}^{-1}\right)$. In such an acidic environment, $\operatorname{Co}(0)$ particles can be leached back in the aqueous 292 solution after deposition. Two concomitant but opposing phenomena emerge: (i) the reduction of $293 \mathrm{Co}(\mathrm{II})$ at the negative overpotential and (ii) the oxidation of $\mathrm{Co}(0)$ due to the $\mathrm{HCl}$ concentration. 294 As a result, the particle seen in Figure 6 is composed of only 52.7 mol.\% of cobalt and 44.7 mol.\% 295 of chloride, characteristic of an ongoing leaching phenomenon.
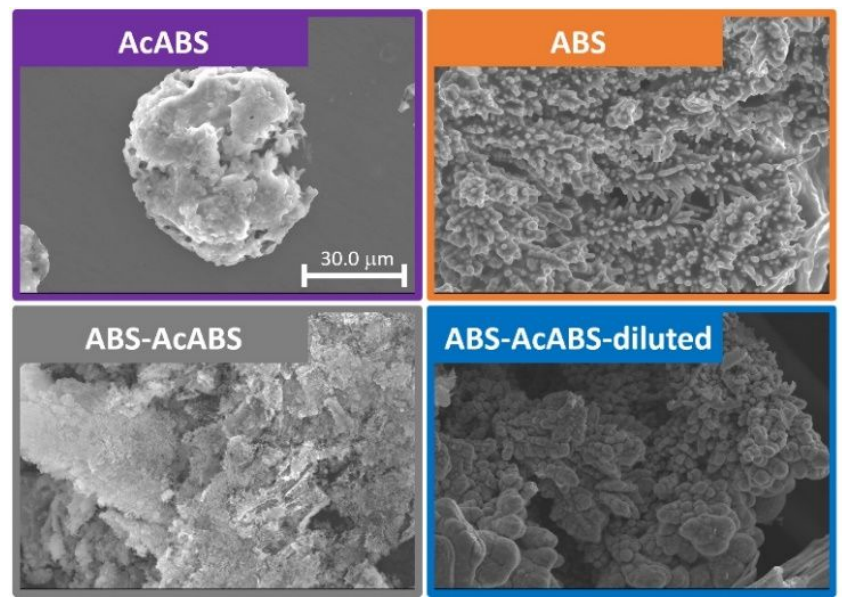

ABS-ACABS-diluted

297

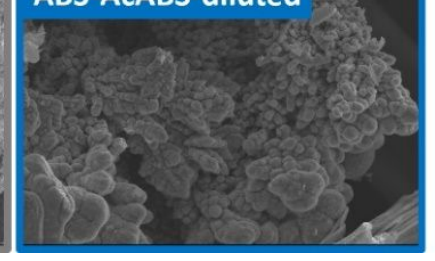

298 Figure 6. SEM-SE images (magnification $\times 1000$ ) of working electrodes after 1 hour of 299 electrodeposition at $-2.00 \mathrm{~V}$ vs. $\mathrm{Ag} / \mathrm{AgCl}$. 
300 Table 1. Elemental analysis of the electrodeposited deposits obtained in ABS, AcABS and ABS301 AcABS (undiluted and diluted) systems after extraction from solutions containing 0.1 mol.L $\mathrm{L}^{-1}$ $302 \mathrm{Co}(\mathrm{II})$.

\begin{tabular}{cccc}
\hline \multirow{2}{*}{ Systems } & \multicolumn{3}{c}{ Elemental analysis (mol.\%) } \\
\cline { 2 - 4 } & $98.9 \pm 12.3$ & $1.1 \pm 0.5$ & $\mathrm{P}$ \\
\hline ABS & $52.7 \pm 23.3$ & $44.7 \pm 18.3$ & $2.6 \pm 1.6$ \\
AcABS & $92.6 \pm 12.5$ & $6.9 \pm 6.3$ & $0.5 \pm 0.1$ \\
ABS-AcABS & $95.6 \pm 16.3$ & $3.3 \pm 2$ & $1.1 \pm 0.6$ \\
ABS-AcABS-diluted & & & \\
\hline
\end{tabular}

303

304 To avoid leaching just after the electrodeposition step, a mixed ABS-AcABS system containing $305\left[\mathrm{P}_{44414}\right] \mathrm{Cl}-\mathrm{NaCl}-\mathrm{HCl}-\mathrm{H}_{2} \mathrm{O}$ is evaluated (composition provided in Table 1). As shown in Figure 3, 306 the partial substitution of $\mathrm{HCl}$ by $\mathrm{NaCl}$ reduces the $\left[\mathrm{H}_{3} \mathrm{O}\right]^{+}$concentration of the IL-rich phase 307 whilst maintaining the required solution acidity to perform the leaching of metals. This system was 308 studied both in its undiluted and diluted form to establish the impact of water and therefore Co(II) 309 complexation, on the quality of the $\mathrm{Co}(0)$ deposits. In the $\mathrm{CV}$ of undiluted $\mathrm{ABS}-\mathrm{AcABS}, \mathrm{E}^{\mathrm{Red}} \mathrm{Co}$ 310 appears at $-1.12 \mathrm{~V} v s . \mathrm{Ag} / \mathrm{AgCl}$ (Figure 5, grey line), similar to that obtained in the ABS system. 311 The composition of the obtained deposit is $92 \mathrm{~mol} . \%$ of cobalt and only $7 \mathrm{~mol} . \%$ chloride. This 312 represents a significant increase in the deposit purity compared to that obtained in AcABS. The 313 presence of $\mathrm{Cl}^{-}$is assigned to (i) the presence of residual $\left[\mathrm{P}_{44414}\right] \mathrm{Cl}$ in the final deposit and (ii) to 314 the small leaching effect from the persistent presence of $\mathrm{HCl}\left(\left[\mathrm{H}_{3} \mathrm{O}\right]^{+}=0.35 \pm 0.04\right.$ mol.L-1). SEM315 SE analysis of the working electrode surface after deposition reveals its complete coverage by a 316 large layer of deposit ( $c f$. Figure 6). The deposit presents a sheet-like structure with no observable 
317 dendrites. This is probably due to the etching of the deposit surface by the remaining $\mathrm{HCl}$ after

318 oxidation of $\operatorname{Co}(0)$ present in the dendritic structures of high surface area.

319 To gain a better understanding on the role of water in the studied system, the IL-rich phase (top 320 phase) of the mixed system ABS-AcABS was isolated after extraction and diluted ( $0.2 \mathrm{~g}$ of water 321 per gram of isolated IL-rich phase). The system was diluted through dropwise addition of water 322 until a shift in the solution colour from blue to light red was observed. By varying the water content 323 of the IL-rich phase after AcABS extraction, essentially transitioning from a water in IL 324 environment to IL as electrolytes in aqueous solutions, the mass transport and interfacial structure 325 at the electrode can be altered resulting in potentially different deposit properties. ${ }^{32-33}$ An 326 additional positive effect of dilution on the Faradic efficiency is the change in Co(II) coordination 327 from chlorocobalt complexes to Co(II) hexahydrate. Dilution of the system results in a positive 328 shift in the onset of the reduction peak from $-1.12 \mathrm{~V} v s . \mathrm{Ag} / \mathrm{AgCl}$ for ABS-ACABS to $-0.90 \mathrm{~V} v s$. $329 \mathrm{Ag} / \mathrm{AgCl}$ for $\mathrm{ABS}-\mathrm{AcABS}-$ diluted. The dilution influences the complexation of cobalt-chloride 330 complexes, thereby increasing the reduction potential in accordance with Nernst's law. A deposit 331 composed of large dendrites was visually observed, further confirmed by SEM-SE (cf. Figure 6). 332 Elemental analysis of the deposit highlights a quasi-pure material composed of $95.5 \mathrm{~mol} . \%$ cobalt. 333 In light of these results, $\left[\mathrm{P}_{44414}\right] \mathrm{Cl}-\mathrm{NaCl}-\mathrm{HCl}-\mathrm{H}_{2} \mathrm{O}$ mixture stands out as promising medium for the 334 recovery of metallic cobalt. The morphology and composition of the obtained deposits can be 335 altered by varying the $\mathrm{NaCl}$ to $\mathrm{HCl}$ ratio and water content, resulting in highly tailored cobalt 336 deposits. However, extraction results displayed in Figure 2 indicate that up to 40 wt. $\%$ of Mn(II) 337 can be co-extracted with Co(II). The question of the selectivity of such a process, starting from an 338 aqueous solution containing a mixture of $\mathrm{Co}(\mathrm{II}), \mathrm{Mn}(\mathrm{II})$ and $\mathrm{Ni}(\mathrm{II})$ thus arises. 


\section{Selective electrodeposition of $\mathrm{Co}$ (II) from $\mathrm{Ni}$ (II) and $\mathrm{Mn}$ (II)}

341 After extraction of a mixture of $0.1 \mathrm{~mol}^{-\mathrm{L}^{-1}}$ of $\mathrm{Co}(\mathrm{II}), \mathrm{Ni}(\mathrm{II})$ and $\mathrm{Mn}(\mathrm{II})$ from ABS and ABS-

342 AcABS systems (Table $\mathrm{S} 1$ of the $\mathrm{ESI}$ ), chronoamperometry experiments at $-2 \mathrm{~V}$ vs $\mathrm{Ag} / \mathrm{AgCl}$ were

343 carried out to selectively reduce cobalt to its metallic state. Results are given in Figure 7. Current

344 densities for all experiments suffer from some oscillations as a result of hydrogen evolution from

345 the reduction of water and/or of $\left[\mathrm{H}_{3} \mathrm{O}\right]^{+}$. The current density slowly decreases with time during 346 deposition in all systems, characteristic of metallic deposition. The reduction of a conductive

347 material such as cobalt can increase the surface area of the electrode and thus the current density 348 in absolute value. This phenomenon is particularly pronounced in the ABS-AcABS-diluted system 349 where the current density is multiplied by a factor of 8 in one hour. The lower viscosity and 350 chloride complexation of this system are beneficial for an efficient deposition of metals. 351 Quantitative compositional analysis of the deposits for the systems presented in Figure 7 and their 352 respective Faradic efficiencies are displayed in Table 2.

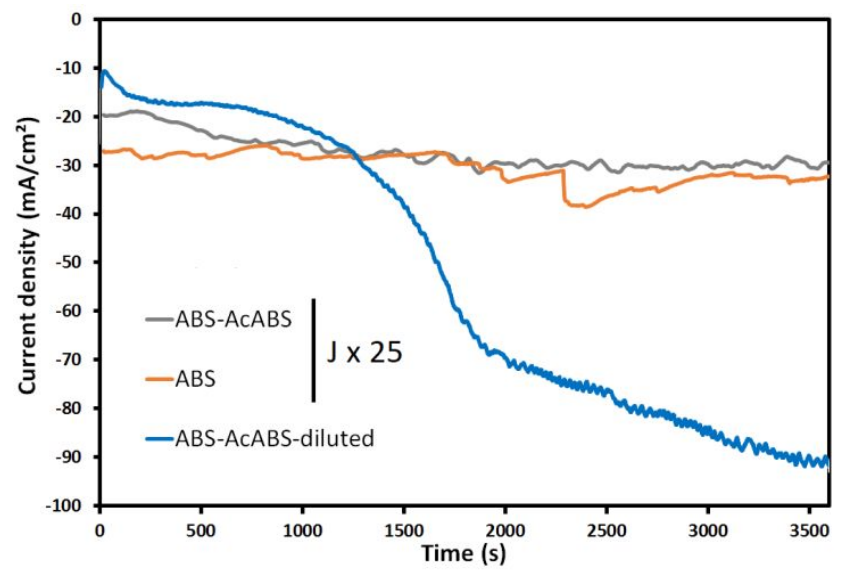

355 Figure 7. Chronoamperometry experiments using a potential of $-2.00 \mathrm{~V}$ vs. $\mathrm{Ag} / \mathrm{AgCl}$ for 1 hour. 356 Current densities (J) are multiplied by 25 for the ABS and ABS-AcABS systems. 
357 For all studied systems, no trace of $\mathrm{Mn}$ (II) and $\mathrm{Ni}$ (II) were recorded, confirming that solely $358 \mathrm{Co}(\mathrm{II})$ is reduced as a metallic species. This is to be expected as $\mathrm{Ni}(\mathrm{II})$ is not extracted to the IL359 rich phase (cf. Figure 1), and $\mathrm{Mn}(\mathrm{II})$ presents a reduction potential of $-1.41 \mathrm{~V} v s$. $\mathrm{Ag} / \mathrm{AgCl}$, lower 360 than that of $\mathrm{Co}(\mathrm{II})(-0.5 \mathrm{~V} v s . \mathrm{Ag} / \mathrm{AgCl}) .{ }^{25} \mathrm{The}$ efficiency of $\mathrm{Co}(\mathrm{II})$ reduction is low in the undiluted 361 ABS and ABS-AcABS systems with a final deposit mass of $0.30 \mathrm{mg}$ and $0.29 \mathrm{mg}$ respectively. 362 Faradic efficiencies indicate that around $30 \%$ of the electrons generated by the potentiostat are 363 devoted to the reduction of $\mathrm{Co}(\mathrm{II})$ to metallic $\mathrm{Co}(0)$ in these systems. Inducing a potential of -2.00 $364 \mathrm{~V}$ vs. $\mathrm{Ag} / \mathrm{AgCl}$ results in an important reduction of water and/or proton to hydrogen. The low 365 energetic yields hinder the industrial application for such processes.

367 Table 2. ICP analysis performed for ABS, ABS-AcABS, and ABS-AcASB-diluted systems. The 368 composition of the deposits and Faraday efficiencies $\left(\mathrm{E}_{\mathrm{F}}\right)$ are given for all systems.

\begin{tabular}{c|ccc}
\hline \multirow{2}{*}{ Deposit Composition } & \multicolumn{3}{|c}{ Extraction Systems } \\
\cline { 2 - 4 } & ABS-AcABS & ABS & $\begin{array}{c}\text { ABS-AcABS- } \\
\text { diluted }\end{array}$ \\
\hline Co (mg) & $0.30 \pm 5 \times 10^{-3}$ & $0.29 \pm 5 \times 10^{-3}$ & $7.2 \pm 0.1$ \\
$\mathrm{Mn}(\mathrm{mg})$ & $<5 \times 10^{-3}$ & $<5 \times 10^{-3}$ & $<5 \times 10^{-3}$ \\
$\mathrm{Ni}(\mathrm{mg})$ & $<5 \times 10^{-3}$ & $<5 \times 10^{-3}$ & $<5 \times 10^{-3}$ \\
\hline $\mathrm{E}_{\mathrm{F}}(\%)$ & 28.9 & 31.6 & 59.7 \\
\hline Co electroplated (mol.\%) & 0.91 & 0.82 & 2.51 \\
\hline
\end{tabular}

369

370 Deposition yields are significantly improved after dilution, with close to twenty fourfold increase 371 in the deposit mass to $7.2 \mathrm{mg}$ in the system ABS-AcABS-diluted. This results in a twofold increase 
372 in the Faradic efficiency to a value of $59.7 \%$. The Faradic yields reported here are reasonably 373 satisfying and were obtained without any optimisation of the electrochemical process. At $-2 \mathrm{~V}$ vs. $374 \mathrm{Ag} / \mathrm{AgCl}$, water or $\left[\mathrm{H}_{3} \mathrm{O}\right]^{+}$present in the medium is expected to be reduced significantly. Carrying 375 out the experiments at a more positive potential would most probably lead to better yields due to 376 a less pronounced reduction or water or $\left[\mathrm{H}_{3} \mathrm{O}\right]^{+}$. Experiments carried out at $-1.5 \mathrm{~V}$ vs. $\mathrm{Ag} / \mathrm{AgCl}$ 377 revealed that deposition of $\mathrm{Co}(\mathrm{II})$ was possible, whereas assigning a potential of $-1 \mathrm{~V}$ at the GC 378 electrode did not yield any reduction of Co(II). It is worth highlighting that the electric charge is 379 of 0.3 and $14 \mathrm{C}$ for the undiluted and diluted ABS-AcABS systems respectively. As a result, even 380 if the Faradic yield is twice higher with the ABS-AcABS-diluted, more electrons will be devoted 381 to the reduction of water in the latter system. However, the cobalt deposition kinetic is more than 38224 times faster in the diluted systems which significantly improves results obtained compared to 383 pure ILs. After 1 hour of chronoamperometric measurements, only $2.5 \mathrm{~mol}$. \% of $\mathrm{Co}$ (II) ions were 384 reduced. This proves that the bath did not suffer from any significant concentration depletion. 385 Larger surface electrodes are required to recover the metal in an acceptable length of time. The 386 current-time transient for the deposition of Co(II) from the ABS-AcABS-diluted system was 387 studied to determine the nucleation process (Figure S7 of the ESI) and was found to follow a 3D 388 instantaneous nucleation growth process.

389 The crystalline structure of the deposits obtained at the end of the chronoamperometry 390 experiments were analysed by XRD analysis with the spectra depicted in Figure $8 . \mathrm{NaCl}$ crystals 391 are highlighted in the ABS-AcABS and ABS systems. This is not surprising as these two solutions 392 contain an important initial $\mathrm{NaCl}$ concentration $(7.6 \mathrm{wt} . \%)$ to induce the formation of two phases.

393 Near the electrode, the deposition of cobalt in ABS-AcABS and ABS systems will most likely 394 release chloride anions from the metallic complexes and locally saturate the solution in $\mathrm{NaCl}$ 
395 inducing the crystallisation of the latter salt. All deposits are composed of metallic $\operatorname{Co}(0)$ 396 crystallised in a hexagonal close packed lattice. However, there are differences in the 397 crystallisation of $\mathrm{Co}(0)$ in the $\mathrm{ABS}$ and ABS-AcABS compared to the ABS-AcABS-diluted 398 system. Focusing on the cobalt metallic peaks $2\left(p_{2}\right)$ and $3\left(p_{3}\right)$ at $44.6^{\circ}$ and $47.5^{\circ}$ respectively, the 399 ratio $\mathrm{R}=\mathrm{p}_{2} / \mathrm{p}_{3}$ differs from one system to another. These two peaks correspond to the crystal 400 orientation (111) and (101) respectively of metallic cobalt. ${ }^{34}$ Concerning the ABS-AcABS-diluted 401 system, $\mathrm{p}_{2}$ presents a higher intensity than $\mathrm{p}_{3}$ resulting in a ratio $\mathrm{R}$ of 1.51 . The opposite 402 phenomenon is reported for ABS-AcABS and ABS systems leading to a ratio of 0.51 and 0.47 403 respectively. This phenomenon highlights a preferential crystalline orientation of metals 404 electrodeposited in concentrated IL solutions compared to diluted IL solutions. Such changes in 405 the crystalline nature of deposits due to the presence of IL was previously reported for the 406 deposition of copper in the presence of $\left[\mathrm{C}_{4} \mathrm{mim}\right]\left[\mathrm{HSO}_{4}\right]$ as additive. ${ }^{35}$

407 The versatility of IL-based ABS and AcABS was recently highlighted for its application in metal 408 extraction ${ }^{6,8,36-37}$ but it is here shown that it can be extended to the electrodeposition of metals. The 409 hydrophilicity of the extracting solution allows to tune and enhance the efficiency of the recovery 410 of pure cobalt and to modify the properties of the resulting deposits. 


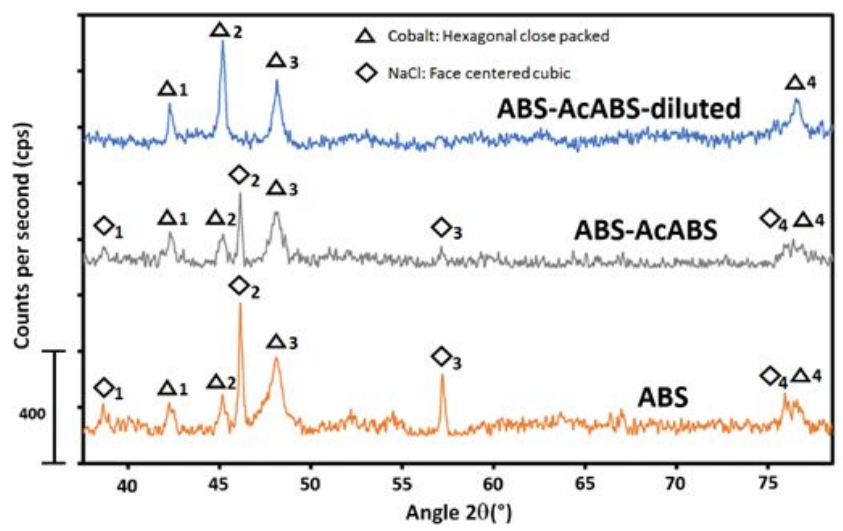

413 Figure 8. XRD diffractograms of deposits obtained after extraction of metals from a mixed 414 solution containing 0.1 mol. $\mathrm{L}^{-1} \mathrm{Co}(\mathrm{II}), \mathrm{Ni}(\mathrm{II})$ and $\mathrm{Mn}(\mathrm{II})$ and electrodeposition at a potential of $4152.00 \mathrm{~V} v s . \mathrm{Ag} / \mathrm{AgCl}$ during 1 hour.

\section{CONCLUSIONS}

418 AcABS and its ABS-AcABS derivative stands out as an efficient, flexible and integrated 419 extraction-separation-purification platform for the recovery of critical metals from primary and 420 secondary ores. By varying the $\mathrm{HCl}$ concentration and the chloride source (either $\mathrm{NaCl}$ or $\mathrm{HCl}$ ), 421 selective separation of $\mathrm{Co}(\mathrm{II})$ from $\mathrm{Ni}(\mathrm{II})$ was achieved whilst controlling the partition of the 422 various system constituents. The distribution of $\mathrm{HCl}$ was found to have a profound influence on 423 the subsequent electrodeposition of $\mathrm{Co}(\mathrm{II})$. To address this, a mixed ABS-AcABS extraction 424 system was proposed which combines the advantages of the AcABS and ABS systems. By varying 425 the water content of the $\left[\mathrm{P}_{44414}\right]$ Cl-rich phase after extraction and separation of $\mathrm{Co}(\mathrm{II})$ from $\mathrm{Ni}$ (II), 426 high quality dendritic deposits of pure metallic cobalt were obtained in presence of $\mathrm{Mn}$ (II) 427 impurities. Furthermore, ABS-AcABS systems can be tailored to obtain metal deposits with varied 428 properties. The results presented in this work demonstrate the applicability of AcABS for a 'one- 
429 pot' approach for the sequential leaching, solvent extraction and electrodeposition of metals.

430 Moreover, this work provides an understanding of the fundamental mechanisms governing the 431 extraction and electrodeposition in AcABS required to extend these findings to the recovery of 432 other critical metals.

\section{ACKNOWLEDGMENT}

435 This work was part of BATRE-ARES project (ERA-MIN/0001/2015) funded by ADEME and 436 FCT. M. Gras would like to acknowledge labex CEMAM and EIT InnoEnergy H2020 for financial 437 support. This work was partly developed within the scope of the project CICECO-Aveiro Institute 438 of Materials, POCI-01-0145-FEDER-007679 (FCT Ref. UID /CTM /50011/2013), financed by 439 national funds through the FCT/MEC and when appropriate co-financed by FEDER under the $440 \quad$ PT2020 Partnership Agreement.

\section{ASSOCIATED CONTENT}

443 Supporting Information. detailed list of chemicals and instruments used, extraction of Co(II), $444 \mathrm{Ni}(\mathrm{II})$ and $\mathrm{Mn}$ (II) in $\mathrm{AcABS}$ as a function of $\mathrm{HCl}$ concentration, IL-rich phase viscosity before 445 and after $\mathrm{Co}$ (II) extraction, extraction in $\mathrm{AcABS}$ as a function of $\mathrm{Co}(\mathrm{II})$ concentration, composition 446 of IL-rich phase after extraction in ABS and ABS-AcABS systems, CV of aqueous Co(II) solutions 447 in the presence of $\mathrm{HCl}$, electrochemical behavior of $\mathrm{Co}(\mathrm{II})$ in $\left[\mathrm{P}_{44414}\right] \mathrm{Cl}$ aqueous solutions, 448 chronometric measurements of $\mathrm{Co}(\mathrm{II})$ deposition from $\left[\mathrm{P}_{44414}\right] \mathrm{Cl}$-rich phase after extraction in 449 AcABS, ABS and ABS-AcABS, nucleation mechanism of Co(II) in mixed ABS-AcABS-diluted 450 system during electrodeposition. 


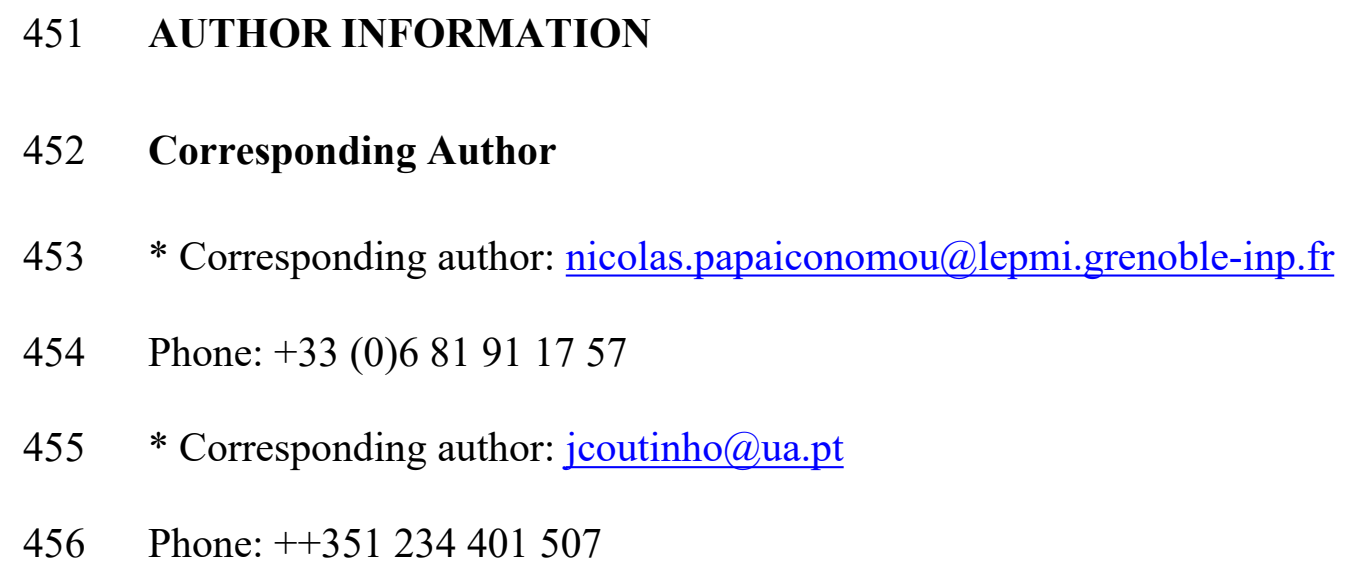


473 5) Wilson, A.M., Bailey, P.J., Tasker, P.A., Turkington, J.R., Grant, R.A., Love, J.B., Solvent 474 extraction: the coordination chemistry behind extractive metallurgy. Chem. Soc. Rev., 2014, 475 43, 123-134. DOI 10.1039/C3CS60275C.

476 6) Gras, M., Papaiconomou, N. Schaeffer, N., Chainet, E., Tedjar, F., Coutinho, J.A.P., Billard, 477 I., Ionic-Liquid-Based Acidic Aqueous Biphasic Systems for Simultaneous Leaching and 478 Extraction of Metallic Ions. Angew. Chem. Int. Ed., 2018, 57, 1563-1566. DOI $479 \quad$ 10.1002/anie.201711068.

480 7) Hallett, J.P., Welton, T., Room-temperature ionic liquids: solvents for synthesis and catalysis. 481 2. Chem. Rev., 2011, 111, 3508-3576. DOI 10.1021/cr1003248.

482 8) Onghena, B., Opsomer, T., Binnemans, K., Separation of cobalt and nickel using a 483 thermomorphic ionic-liquid-based aqueous biphasic system. Chem. Commun., 2015, 51, 484 15932-15935. DOI 10.1039/C5CC06595J.

485 9) Shahriari, S., Neves, C.M.S.S., Freire, M.G., Coutinho, J.A.P., Role of the Hofmeister Series 486 in the Formation of Ionic-Liquid-Based Aqueous Biphasic Systems. J. Phys. Chem. B, 2012, $487 \quad 116,7252$. DOI $10.1021 / j p 300874 u$.

488 10) Thuy Pham, T.P., Cho, C.W., Yun, Y.S., Environmental fate and toxicity of ionic liquids: a 489 review. Water Res., 2010, 44, 352. DOI 10.1016/j.watres.2009.09.030.

490 11) Fu, J., Yang, Y.I., Zhang, J., Chen, Q., Shen, X., Gao, Y.Q., Structural Characteristics of 491 Homogeneous Hydrophobic Ionic Liquid- $\mathrm{HNO}_{3}-\mathrm{H}_{2} \mathrm{O}$ Ternary System: Experimental Studies 492 and Molecular Dynamics Simulations. J. Phys. Chem. B, 2016, 120, 5194. DOI $493 \quad$ 10.1021/acs.jpcb.6b01214. 
494 12) Mazan, V., Boltoeva, M.Y., Tereshatov, E.E., Folden III, C.M., Mutual solubility of water and 495 hydrophobic ionic liquids in the presence of hydrochloric acid. $R S C A d v ., 2016,6,56260$. DOI $496 \quad$ 10.1039/C6RA06791C.

497 13) Vander Hoogerstraete, T., Wellens, S., Verachtert, K., Binnemans, K., Removal of transition 498 metals from rare earths by solvent extraction with an undiluted phosphonium ionic liquid: 499 separations relevant to rare-earth magnet recycling. Green Chem., 2013, 15, 919. DOI $500 \quad$ 10.1039/C3GC40198G.

501 14) Wellens, S., Thijs, B., Binnemans, K., An environmentally friendlier approach to 502 hydrometallurgy: highly selective separation of cobalt from nickel by solvent extraction with 503 undiluted phosphonium ionic liquids. Green Chem., 2012, 14, 1657-1665. DOI $504 \quad 10.1039 /$ C2GC35246J.

505 15) European Commission, Study on the review of the list of Critical Raw Materials. Luxembourg: 506 Publications Office of the European Union, 2017. DOI 10.2873/876644.

507 16) Larsson, K. Binnemans, K., Selective extraction of metals using ionic liquids for nickel metal 508 hydride battery recycling. Green Chem., 2014, 16, 4595-4603. DOI 10.1039/C3GC41930D.

509 17) Neves, C.M.S.S., Ventura, S.P.M., Freire, M.G., Marrucho, I.M., Coutinho, J.A.P., Evaluation 510 of Cation Influence on the Formation and Extraction Capability of Ionic-Liquid-Based 511 Aqueous Biphasic Systems. J. Phys. Chem. B, 2009, 113, 5194-5199. DOI 10.1021/jp900293v

512 18) Högfeldt, E. IUPAC Stability constants of metal-ion Complexes Part A: Inorganic ligands; 513 IUPAC; Pergamon Press, 1982.

514 19) Schaeffer, N., Passos, H., Gras, M., Mogilireddy, V., Leal, J.P., Pérez-Sánchez, G., Gomes, 515 J.R.B., Billard, I., Papaiconomou, N., Coutinho, J.A.P., Mechanism of ionic-liquid-based 
516 acidic aqueous biphasic system formation. Phys. Chem. Chem. Phys., 2018, 20, 9838-9846.

$517 \quad$ DOI $10.1039 / \mathrm{c} 8 \mathrm{cp} 00937 \mathrm{f}$.

518 20) Onghena, B., Valgaeren, S., Vander Hoogerstraete, T., Binnemans, K., Cobalt(II)/nickel(II)

519 separation from sulfate media by solvent extraction with an undiluted quaternary phosphonium $520 \quad$ ionic liquid. $R S C A d v$., 2017, 7, 35992-35999. DOI 10.1039/C7RA04753C.

521 21) Papaiconomou, N., Svecova, L., Bonnaud, C., Cathelin, L., Billard, I., Chainet, E., Possibilities 522 and limitations in separating Pt(IV) from Pd(II) combining imidazolium and phosphonium 523 ionic liquids. Dalton Trans., 2015, 44, 20131-20138. DOI 10.1039/c5dt03791c.

524 22) Hsieh, Y.T., Lai, M.C., Huang, H.L., Sun, I.W., Speciation of cobalt-chloride-based ionic 525 liquids and electrodeposition of Co wires. Electrochim. Acta, 2014, 117, 217-223. DOI $526 \quad 10.1016 / j$. electacta.2013.11.120.

527 23) Tsunashima, K., Sugiya, M., Physical and electrochemical properties of low-viscosity 528 phosphonium ionic liquids as potential electrolytes. Electrochem. Commun., 2007, 9, 2353$529 \quad$ 2358. DOI 10.1016/j.elecom.2007.07.003.

530 24) MacFarlane, D.R., Tachikawa, N., Forsyth, M., Pringle, J.M., Angell, C.A., Energy 531 applications of ionic liquids. Energy Environ. Sci., 2014, 7, 232-250. DOI $532 \quad 10.1039 / \mathrm{C} 3 \mathrm{EE} 42099 \mathrm{~J}$.

533 25) Bard, A., Parsons, J., Jordan, R., Standard potentials in aqueous solutions, CRC Press, 1985.

534 26) Lechat, S., Khan, M.A., Bouet, G., Spectrophotometric study of cobalt(II) chloride complexes 535 in ethanol and propan-2-ol. Inorg. Chim. Acta, 1993, 211, 33-36. DOI 10.1016/S0020$536 \quad 1693(00) 82840-6$. 
537 27) Matulis, J., Slizys, K., On Some Characteristics of Cathodic Processes in Nickel 538 Electrodeposition. Electrochim. Acta, 1964, 9, 1177-1188. DOI 10.1016/0013$539 \quad 4686(64) 85009-X$.

540 28) Piatti, R.C.V., Arvia, A.J., Podesta, J.J., The Electrochemical Kinetic Behaviour of Nickel in 541 Acid Aqueous Solutions Containing Chloride and Perchlorate Anions. Electrochim. Acta. $542 \quad \mathbf{1 9 6 9}, 14,541-560$. DOI 10.1016/0013-4686(69)87040-4.

543 29) Chassaing, E., Joussellin, M., Wiart, R., The Kinetics of Nickel Electrodeposition Inhibition by 544 Adsorbed Hydrogen and Anions. J. Electroanal. Chem., 1983, 157, 75-88. DOI $545 \quad 10.1016 / \mathrm{S} 0022-0728(83) 80377-5$.

546 30) Suryanto, B.H.R., Lu, X., Chan, H.M., Zhao, C., Controlled electrodeposition of cobalt oxides 547 from protic ionic liquids for electrocatalytic water oxidation. RSC Adv., 2013, 3, 20936-20942. 548 DOI 10.1039/C3RA43614D.

549 31) Crundwell, F.K., M.S. Moats, V. Ramachandran, T.G. Robinson, W.G. Davenport, W.G., $550 \quad$ Extractive metallurgy of nickel, cobalt and platinum group metals, Elsevier, 2011.

551 32) Abbott, A.P., Model for the Conductivity of Ionic Liquids Based on an Infinite Dilution of 552 Holes. Chem.Phys.Chem., 2005, 6, 2502-2505. DOI 10.1002/cphc.200500283.

553 33) Kornyshev, A.A., Double-Layer in Ionic Liquids: Paradigm Change? J. Phys. Chem. B, 2007, $554 \quad 111,5545-5557$. DOI 10.1021/jp067857o.

555 34) Qin, W., Yang, C., Ma, X., Lai, S., Selective synthesis and characterization of metallic cobalt, 556 cobalt/platinum, and platinum microspheres. J. Alloys Compd., 2011, 509, 338-342. DOI $557 \quad$ 10.1016/j.jallcom.2010.09.022. 
558 35) Zhang, Q.B., Hua, Y.X., Wang, Y.T., Lu, H.J., Zhang, X.Y., Effects of ionic liquid additive $559 \quad[\mathrm{BMIM}] \mathrm{HSO}_{4}$ on copper electro-deposition from acidic sulfate electrolyte. Hydrometallurgy, $560 \quad 2009,98,291-297$. DOI 10.1016/j.hydromet.2009.05.017.

561 36) Blesic, M., Nimal Gunaratne, H.Q., Jacquemin, J., Nockemann, P., Olejarz, S., Seddon, K.R., 562 Strauss, C.R., Tunable thermomorphism and applications of ionic liquid analogues of Girard's 563 reagents. Green Chem., 2014, 16, 4115-4121. DOI 10.1039/C4GC01159G.

564 37) Vander Hoogerstraete, T., Onghena, B. Binnemans, K., Homogeneous Liquid-Liquid 565 Extraction of Metal Ions with a Functionalized Ionic Liquid. J. Phys. Chem. Lett., 2013, 4, $566 \quad 1659-1663$. DOI $10.1021 / \mathrm{jz} 4005366$.

567 568 


\section{TABLE OF CONTENT (TOC)}

570

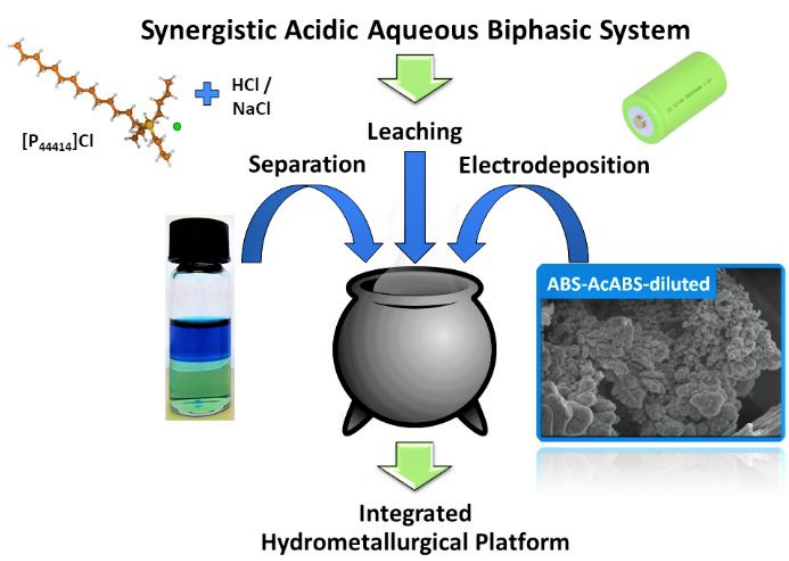

571

Hydrometallurgical Platform

572

\section{SYNOPSIS}

574 The potential of acidic aqueous biphasic system (AcABS) is extended and proposed as a new

575 extraction-separation platform for the integrated hydrometallurgical treatment of critical metals

576 from leaching to electrodeposition. 